Gut, 1980, 21, 469-474

\title{
Ulcerative colitis and pregnancy
}

\author{
C P WILLOUGHBY AND S C TRUELOVE
}

From the Nuffield Department of Clinical Medicine, The John Radcliffe Hospital, Oxford

SUMMARY A survey has been made of pregnancy occurring in patients who were attending the Ulcerative Colitis Clinic at Oxford during the 20-year period, 1960-79 inclusive. There were 256 married women of child-bearing age who attended during this period. Of these, 100 were excluded from the survey for various reasons, such as that they had completed their family before the onset of the ulcerative colitis, had already had an hysterectomy, or had a proctocolectomy before their first pregnancy. Of the remaining 156 patients, nine could not be traced. Full details were obtained from 147 patients, virtually all of whom were interviewed. The fertility of these patients was normal. Of the 147 women, $119(81 \%)$ had conceived and only $10(6.8 \%)$ were involuntarily infertile. The size of family approximated to that found in the general British population. The overall outcome of the pregnancies was similar to that in the general British population. The patients in whom the disease was quiescent at the start of pregnancy fared particularly well. Those with active disease had a somewhat lower chance of producing a normal live baby. The small group of patients in whom the disease was severe had a much lower chance of a normal outcome. Patients in whom the ulcerative colitis was quiescent at the beginning of pregnancy had a good chance of remaining symptom-free throughout the pregnancy and puerperium. Even if the colitis recurred, it was likely to be mild and responsive to medical treatment. By contrast, when the ulcerative colitis was active at the start of pregnancy, most patients continued to have symptoms in spite of medical treatment. Some patients had their first attack of ulcerative colitis during pregnancy or the puerperium. In contrast to previous experience the attacks were generally mild and responded to medical treatment. Medical treatment with corticosteroids or sulphasalazine appeared to have no obvious deleterious effects on the fetus or new-born child.

Ulcerative colitis frequently begins in adolescence or early adult life and therefore coexists with the reproductive years of many of the women who develop this disease. The major questions that arise are four-fold: (1) Is fertility normal in patients with ulcerative colitis? (2) Does ulcerative colitis affect the outcome of the pregnancy? (3) Does pregnancy make the colitis worse? (4) Does medical treatment for ulcerative colitis improve the outcome or does it have dangerous side-effects on either mother or child?

Several previous studies ${ }^{1-7}$ have dealt with these issues but there has been no major survey for the past 15 years, during which time various developments in medical treatment have occurred.

We are therefore reporting our experience with the relevant patients who were attending the Ulcerative Colitis Clinic at the Radcliffe Infirmary, Oxford, during the 20-year period, 1960-79 inclusive.

\section{Methods}

PATIENTS

During the period under survey, a total of 256 married women below the age of 45 years attended the Ulcerative Colitis Clinic. Of these 256 patients, 100 were excluded for the following reasons: In 91 patients, the family was complete before the onset of ulcerative colitis. In five patients, a hysterectomy had been performed before the onset of ulcerative colitis. In three patients, a proctocolectomy with permanent ileostomy had been carried out before their first pregnancy. (Some other patients had pregnancies both before and after a proctocolectomy with permanent ileostomy and we have excluded any post-ileostomy pregnancies in our analysis.) One patient, whose ulcerative colitis had begun in childhood, ceased to attend the clinic on moving to another area and subsequently died before having a family.

Of the remaining 156 patients, nine have not been 
Table 1 Outcome of 216 pregnancies in women with ulcerative colitis

\begin{tabular}{lrr}
\hline Outcome & Number & $(\%)$ \\
\hline Normal live birth & 170 & $(78 \cdot 8)$ \\
Congenital abnormality & 5 & $(2 \cdot 3)$ \\
Spontaneous abortion & 23 & $(10 \cdot 6)$ \\
Therapeutic abortion & 9 & $(4 \cdot 2)$ \\
Stillbirth & 2 & $(0 \cdot 9)$ \\
Pregnant at end of survey & 7 & $(3 \cdot 2)$ \\
Total & 216 & $(100 \cdot 0)$ \\
\hline
\end{tabular}

traced. Details about the 147 patients with whom we have maintained contact were obtained by personal interview based upon a standard set of questions, supplemented by information derived from their hospital records, both in connection with the ulcerative colitis and their obstetrical histories.

\section{Results}

\section{FER TILITY}

Our results show that women with ulcerative colitis appear to be normally fertile. Of the 147 married women interviewed, $119(81 \%)$ have conceived and only 28 have not. Among these 28 infertile women, there were 18 in whom the infertility was voluntary. Six of them were young women who had only been married for a short time and who had not yet decided to start a family. Among the remaining 12 patients, there were eight who did not wish to have a family, one who had made a late marriage and decided not to have children, and three who were given medical advice not to have children because of their disease. In one case, this advice came from the family doctor and in the other two from hospital specialists (not in our own area). In any event, if these 18 women with voluntary infertility are excluded from the total, $92.2 \%$ of the remaining 129 patients were fertile.

In the remaining 10 of the 28 infertile women, the infertility was involuntary. Seven of the married couples had been investigated for sterility and in three instances the husband was oligospermic; one of the women suffered from a prolactinoma. In any event, the incidence of involuntary infertility, which affected 10 out of the 147 married couples $(6.8 \%)$, was not high.

Previous authors have expressed the opinion that women with ulcerative colitis are normally fertile but in general their evidence has not been strong. Crohn et al. ${ }^{2}$ reported on 110 women who had had 150 pregnancies but failed to mention the number who were sterile. Banks et al. ${ }^{4}$ reported that 46 out of 133 women became pregnant $(42 \%)$ but from their data it is impossible to determine the fertility among those in the reproductive years. Likewise, de Dombal et al. ${ }^{5}$ reported that 72 women out of 229 in the reproductive years became pregnant $(31 \%)$, a figure which was necessarily a gross underestimate of the potential fertility because of the short period of follow-up. Our present results are strong evidence that, in recent decades, women with ulcerative colitis have been as fertile as those in the general population.

\section{EFFECT OF ULCERATIVE COLITIS ON PREGNANCY}

During the 20-year period under review, there were 216 pregnancies among the 119 married women who conceived. Table 1 shows that the vast majority of the pregnancies resulted in normal live births. Among these, there were 12 babies who were of low birth weight (less than $2.5 \mathrm{~kg}$ ) but who then developed normally. The proportion of babies of low birth weight in our entire series is similar to that occurring in the general population. ${ }^{8}$ Seven of the women were still pregnant at the end of the period of study and in all these patients the pregnancy was proceeding uneventfully.

Five children were abnormal at birth. Two of them suffered from cerebral palsy; one of these was delivered normally but was premature, while the other was also premature but was delivered by Caesareaan section because of failure of fetal growth. Among the other three infants, one had congenital dislocation of the hips which has been treated successfully by splints, and the remaining two both had hypospadias which will need surgical correction.

Table 2 Outcome of pregnancy in relation to the state of ulcerative colitis at the time of conception

\begin{tabular}{|c|c|c|c|c|c|c|c|}
\hline & $\begin{array}{l}\text { Normal live } \\
\text { birth }\end{array}$ & $\begin{array}{l}\text { Congenital } \\
\text { abnormality }\end{array}$ & $\begin{array}{l}\text { Spontaneous } \\
\text { abortion }\end{array}$ & $\begin{array}{l}\text { Therapeutic } \\
\text { abortion }\end{array}$ & Stillbirth & $\begin{array}{l}\text { Still } \\
\text { pregnant at } \\
\text { end of survey }\end{array}$ & Total \\
\hline Total & & & & & & & 216 \\
\hline
\end{tabular}

* 1 cerebral palsy; 1 hypospadias; 1 congenital dislocation of hips.

$\dagger 1$ cerebral palsy; 1 hypospadias. 
Table 3 Effect of pregnancy on the course of ulcerative colitis (209 completed pregnancies)

\begin{tabular}{|c|c|c|c|}
\hline \multicolumn{3}{|c|}{ State of ulcerative colitis } & \multirow{2}{*}{$\begin{array}{r}\text { Total } \\
129\end{array}$} \\
\hline $\begin{array}{l}\text { In remission } \\
\text { at conception }\end{array}$ & $\begin{array}{l}\text { Remission maintained } \\
\text { Relapse: } \\
\text { 1st trimester } \\
\text { 2nd trimester } \\
\text { 3rd trimester } \\
\text { Puerperium }\end{array}$ & $\left.\begin{array}{r}90 \\
18 \\
7 \\
8 \\
6\end{array}\right\} 39$ & \\
\hline $\begin{array}{l}\text { Clinically active } \\
\text { at conception }\end{array}$ & $\begin{array}{l}\text { Remission } \\
\text { Improvement } \\
\text { No change } \\
\text { Worse } \\
\text { Worse in puerperium }\end{array}$ & $\begin{array}{r}13 \\
9 \\
15 \\
14 \\
4\end{array}$ & 55 \\
\hline $\begin{array}{l}\text { First attack during } \\
\text { pregnancy }\end{array}$ & $\begin{array}{l}\text { 1st trimester } \\
\text { 2nd trimester } \\
\text { 3rd trimester }\end{array}$ & $\begin{array}{l}8 \\
7 \\
1\end{array}$ & 16 \\
\hline $\begin{array}{l}\text { First attack during } \\
\text { puerperium }\end{array}$ & & 9 & $\begin{array}{r}9 \\
209\end{array}$ \\
\hline
\end{tabular}

This incidence of congenital abnormalities is roughly that found in the general population. ${ }^{9}$

A spontaneous abortion occurred in 23 of the pregnancies $(10.6 \%)$, which again corresponds with the expected figure. ${ }^{10}$

Nine of the pregnancies were terminated by a therapeutic abortion. In five, the abortion was performed for social reasons not connected with the ulcerative colitis. In the remaining four, the colitis became more active in the first trimester and the termination of pregnancy was advised on medical grounds, in two cases by specialists and in two by the general practitioner. No woman was advised by us to have her pregnancy terminated.

There were two stillbirths, one of which occurred in another hospital after a prolonged labour of three days' duration, while the other was premature and there was severe fetal distress. This stillbirth rate of 9 per 1000 births is well within the expected figure.

Apart from the two stillbirths, there were no perinatal deaths. The total perinatal mortality was therefore 9 per 1000 births, which is lower than the rate for the Oxford region in 1978, which was itself one of the three regions with the lowest rate in England and Wales.11

Additional information accrues if the pregnancies are analysed in more detail to take account of the state of the ulcerative colitis at the time of con- ception. Table 2 shows that the patients whose ulcerative colitis was quiescent when they conceived were more likely to produce a normal live baby than those who conceived when the colitis was clinically active.

\section{EFFECT OF PREGNANCY ON ULCERATIVE COLITIS}

It has become conventional to follow the classification of Abramson et al. ${ }^{1}$ when considering the effect of pregnancy on the course of ulcerative colitis. They divided patients into four categories:

1. Patients with established ulcerative colitis which is quiescent at the time of conception.

2. Patients with active ulcerative colitis at the time of conception.

3. Patients who develop ulcerative colitis during pregnancy.

4. Patients who develop ulcerative colitis in the puerperium (which we have taken to be the three months after delivery).

Table 3 shows our own data classified according to the above scheme. Out of the 129 pregnancies in which the colitis was quiescent at the time of conception, $90(69.8 \%)$ of the patients remained free from colitic symptoms throughout pregnancy and the puerperium. In the remaining 39 pregnancies, relapse occurred and this was most likely in the first trimester, a finding which agrees with previous observations. ${ }^{256}$ There were six patients who remained free from symptoms during pregnancy but who relapsed in the puerperium; an additional three patients had an attack of colitis in the puerperium as well as having had a relapse during the pregnancy. Some earlier workers found that relapse was particularly common during the puerperium but the present results show that this is no longer the case.

When pregnancy occurred in patients with active ulcerative colitis, the course of the colitis was less favourable. Out of 55 pregnancies in this category, in only a minority did the disease become quiescent (13) or show improvement (nine). In 29 pregnancies $(52.7 \%)$ the colitis was unchanged or became worse. In four patients, there was a flare-up of symptoms in the puerperium.

Sixteen patients had their first attack of ulcerative

Table 4 Relapses of ulcerative colitis in patients who were in remission at conception

\begin{tabular}{|c|c|c|c|}
\hline & Number of pregnancies & $\begin{array}{l}\text { Number of relapses during } \\
\text { pregnancy or puerperium }\end{array}$ & Percentage relapses \\
\hline Maintenance therapy with sulphasalazine & 49 & 17 & $34.7\left\{\begin{array}{l}x^{2}=1.472 \\
\mathrm{n}=1\end{array}\right.$ \\
\hline $\begin{array}{l}\text { No maintenance therapy } \\
\text { Sulphasalazine stopped after becoming pregnant }\end{array}$ & $\begin{array}{r}77 \\
3\end{array}$ & $\begin{array}{r}19 \\
2\end{array}$ & $24 \cdot 7 \int_{P}>0 \cdot 10$ \\
\hline
\end{tabular}


Table 5 Outcome of pregnancy related to sulphasalazine maintenance treatment for ulcerative colitis in remission at conception

\begin{tabular}{|c|c|c|c|c|c|c|c|}
\hline & $\begin{array}{l}\text { Number of } \\
\text { pregnancies }\end{array}$ & $\begin{array}{l}\text { Normal } \\
\text { live birth }\end{array}$ & $\begin{array}{l}\text { Congenital } \\
\text { abnormality }\end{array}$ & $\begin{array}{l}\text { Spontaneous } \\
\text { abortion }\end{array}$ & $\begin{array}{l}\text { Therapeutic } \\
\text { abortion }\end{array}$ & Stillbirth & $\begin{array}{l}\text { Pathological } \\
\text { jaundice }\end{array}$ \\
\hline $\begin{array}{l}\text { Maintenance therapy with sulphasalazine } \\
\text { No maintenance therapy } \\
\text { Sulphasalazine stopped after becoming }\end{array}$ & $\begin{array}{l}49 \\
77\end{array}$ & $\begin{array}{l}39 * \\
66 *\end{array}$ & $\begin{array}{l}1 \dagger \\
2 \ddagger\end{array}$ & $\begin{array}{l}7 \\
7\end{array}$ & $\begin{array}{l}2 \\
2\end{array}$ & $\begin{array}{l}\mathbf{0} \\
\mathbf{0}\end{array}$ & $\begin{array}{l}3 \\
3\end{array}$ \\
\hline pregnant & 3 & 3 & $\mathbf{0}$ & 0 & $\mathbf{0}$ & $\mathbf{0}$ & $\mathbf{0}$ \\
\hline
\end{tabular}

colitis during pregnancy, the onset being commonly in the first or second trimesters. Only four of the attacks were severe and three of these were in the first trimester. The colitis was adequately controlled in all cases by medical treatment and the 16 pregnancies resulted in 14 healthy live babies. In the past, ulcerative colitis beginning in pregnancy was dangerous with a $15 \%$ maternal mortality rate re $^{12}$ but modern treatment has completely changed this. Indeed, there was no maternal mortality in our entire series.

Nine patients developed ulcerative colitis in the puerperium. All but one of the attacks were mild and the other one was of moderate severity. This is in contrast with earlier findings that ulcerative colitis beginning in the puerperium tends to run a severe course. ${ }^{4}$

\section{EFFECT OF MEDICAL TREATMENT}

Taking the 129 pregnancies occurring when the ulcerative colitis was quiescent, they can be divided into those during which the patient was on maintenance therapy with sulphasalazine throughout the entire pregnancy and those in which no sulphasalazine was used. Table 4 shows that the relapse rate was somewhat higher with sulphasalazine than without, although the difference is not statistically significant. However, as this finding does not represent the outcome in a controlled therapeutic trial, it is difficult to know what importance to attach to it, especially as many of the women who did not take sulphasalazine had been in prolonged remission without treatment before becoming pregnant.

Table 5 summarises the outcome of the pregnancy according to whether the patients were receiving maintenance treatment with sulphasalazine or not. It can be seen that, with the possible exception of spontaneous abortion, sulphasalazine had no harmful effect on the outcome of pregnancy. In particular, congenital abnormalities were not increased. In addition, pathological jaundice in the new-born, which we have defined as jaundice requiring medical treatment, was little different in the two groups. Of the six babies with pathological jaundice, five were treated with ultraviolet light therapy and the only one who required exchange transfusion was born to a mother not receiving sulphasalazine.

Taking the patients whose ulcerative colitis was clinically active at some stage during pregnancy, any therapy they received and the outcome of the pregnancy is summarised in Table 6. It can be seen that, in general, the more extensive the treatment the more likely it was that the pregnancy would not proceed to a normal live birth. This is particularly shown in the patients who were treated with a combination of oral corticosteroids, topical corticosteroids, and sulphasalazine. The generally un-

Table 6 Outcome of pregnancy in relation to treatment of active ulcerative colitis during pregnancy

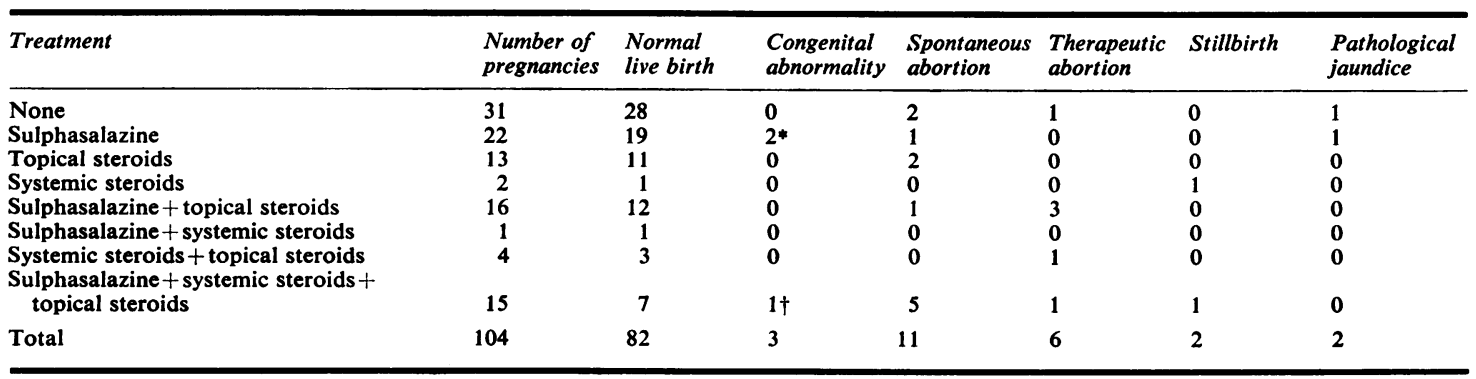

- 1 cerebral palsy; 1 hypospadias.

†1 cerebral palsy. 
favourable course in this group of patients was probably due to the severity of the ulcerative colitis rather than to the effects of medical therapy.

It is interesting that pathological jaundice was no more frequent in the babies of patients who received sulphasalazine than in those of patients who did not.

It is somewhat disturbing that there were three cases of congenital abnormality in the babies born to the 54 mothers treated with sulphasalazine, whereas there were none in the 50 whose mothers had received either no treatment or corticosteroids alone. However, we have already shown that, when the ulcerative colitis was quiescent at the start of pregnancy, treatment with sulphasalazine had no effect on the risk of producing a congenitally abnormal child (Table 5). We therefore consider it more likely that the clinical activity of the ulcerative colitis was the responsible factor rather than the use of sulphasalazine as treatment.

\section{Discussion}

The present study has provided definite answers to the four questions posed in the introduction to this article.

\section{FER TILITY}

Women with ulcerative colitis appear to have a normal chance of becoming pregnant. This conclusion has been reached by various authors of previous studies but on the basis of inadequate data. In our own series, the overall rate of involuntary infertility $(6.8 \%)$ is similar to that estimated for the general population in this country $(10 \%) \cdot{ }^{13}$ It is also worth mentioning that the family size for our married female patients approximates to the normal value for this society, being 2.03 children per fertile married woman, especially when it is remembered that 40 of our patients intend to have additional children in the future.

\section{OUTCOME OF PREGNANCY}

The overall outcome of pregnancy in women with ulcerative colitis is essentially normal. However, there is an advantage if a woman with ulcerative colitis becomes pregnant when the disease is in clinical remission, as the chance of her producing a normal live baby is then conspicuously good, even though some of these patients are liable to have a recurrence of active ulcerative colitis during the course of pregnancy. Patients with active ulcerative colitis at the time of conception have a lower chance of producing a normal live baby, although the chance is only substantially reduced if the disease becomes severe and requires heavy medical treat- ment. Such patients are few and, as a result, the general outcome is favourable.

\section{EFFECT OF PREGNANCY ON ULCERATIVE COLITIS}

If the ulcerative colitis is quiescent at the start of pregnancy, there is a good chance that the disease will remain in remission throughout pregnancy and the puerperium. If relapse does occur, this is most likely to happen in the first trimester. Even if relapse occurs, the risk to the mother is nowadays negligible, provided that the ulcerative colitis is treated vigorously.

Women with ulcerative colitis which is symptomatic at the start of pregnancy are likely to continue to have symptoms throughout the pregnancy in spite of medical treatment. This provides an additional reason for advising married women with this disease to avoid, as far as possible, becoming pregnant while the ulcerative colitis is active.

We have found no undue liability of patients with established ulcerative colitis to suffer from a relapse of the disease during the puerperium, a result which conflicts with previous findings.

It was previously found that when ulcerative colitis began during pregnancy or the puerperium, it was frequently severe. This has not been our own recent experience and this may reflect the beneficial effects of modern medical treatment.

In the past, it has been suggested that a severe attack of ulcerative colitis occurring in the first trimester of pregnancy should be regarded as an indication for therapeutic abortion. ${ }^{12}$ Our own experience is opposed to this view. Although four of our patients had a pregnancy terminated on medical advice, there was no evidence that this procedure improved the course of the colitis and we judge that it is preferable to treat the disease in the same way as one would in a non-pregnant patient.

\section{EFFECT OF TREATMENT}

The married women in our present series suffered from no maternal mortality, were normally fertile, and usually produced a normal live baby. This is prima facie evidence that modern medical treatment has been beneficial but it is difficult to assemble proof with the type of study now presented.

There was no evidence that any of the mothers were harmed by the medical treatments employed, which were essentially corticosteroids and sulphasalazine. As far as the fetus is concerned, animal experiments have suggested that the use of corticosteroids may lead to spontaneous abortion or to congenital abnormalities ${ }^{14}{ }^{15}$ but studies in man have yielded contradictory results. ${ }^{16} 17$ In the present survey, there was no indication that the use of 
corticosteroids was associated with any enhanced risk of congenital abnormalities. Although systemic corticosteroid therapy has been implicated in the production of placental insufficiency, ${ }^{17}$ the incidence of low birth-weight babies in this survey was the same in mothers who had received steroid treatment during pregnancy $(18.9 \%)$ as in those with active ulcerative colitis who had not done so $(18 \cdot 3 \%)$.

The main theoretical risk of using sulphasalazine throughout pregnancy and the puerperium is that the baby might suffer from kernicterus. ${ }^{18}$ Sulphasalazine and its principal metabolites are known to cross the placenta ${ }^{1819}$ and could displace unconjugated bilirubin from binding sites on plasma albumin. Sulphapyridine also enters breast milk.1920 However, no evidence has been found of any adverse clinical effects on the children born to our patients during the past 20 years and there are no recorded cases in the literature.

\section{Recommendations}

The results of the present survey enable us to make two practical recommendations:

1. Whenever feasible, a woman with ulcerative colitis should plan her family so that she conceives only when the disease is quiescent.

2. Active ulcerative colitis during pregnancy should be treated with corticosteroids and sulphasalazine in the same way as in non-pregnant patients.

We wish to thank Mrs Anne Churchill for clerical assistance during the course of the survey, and Mrs Zena Jennings for typing the manuscript.

\section{References}

${ }^{1}$ Abramson D, Jankelson IR, Milner, LR. Pregnancy in idiopathic ulcerative colitis. Am J Obstet Gynecol 1951; 61: 121-9.

${ }^{2}$ Crohn BB, Yarnis H, Crohn EB, et al. Ulcerative colitis and pregnancy. Gastroenterology 1956; 30: 391-403.
${ }^{3}$ MacDougall I. Ulcerative colitis and pregnancy. Lancet 1956; 2: 641-3.

${ }^{4}$ Banks BM, Korelitz BI, Zetzel L. The course of nonspecific ulcerative colitis: review of twenty years' experience and late results. Gastroenterology 1957; 32: 983-1012.

${ }^{5}$ de Dombal FT, Watts JM, Watkinson G, et al. Ulcerative colitis and pregnancy. Lancet 1965; 2: 599-601.

${ }^{6} \mathrm{McEwan}$ HP. Ulcerative colitis in pregnancy. Proc Roy Soc Med 1972; 65: 279-81.

${ }^{7}$ Webb MJ, Sedlack RE. Ulcerative colitis in pregnancy. Med Clin N Amer 1974; 58: 823-7.

${ }^{8}$ Donald I. Practical obstetric problems. 4th ed. London: Lloyd-Luke; 1974.

${ }^{9}$ Jolly H. Diseases of children. 3rd ed. Oxford: Blackwell Scientific Publications, 1976.

${ }^{10}$ Stevenson AC, Dudgeon MY, McClure HI. Observations on the results of pregnancies in women resident in Belfast. Ann Hum Genet 1959; 23: 395-414.

${ }^{11}$ Parliament. Perinatal and infant mortality. $\mathrm{Br}$ Med $\mathrm{J}$ 1979; 1 : 1716.

${ }^{12}$ Fielding JF. Inflammatory bowel disease and pregnancy. Br J Hosp Med 1976: 15: 345-52.

${ }^{13}$ Harrison RF. Infertility in women. Br J Hosp Med 1977; 17: 45-57.

${ }^{14}$ Fraser FC, Fainstat TD. Production of congenital defects in offspring of pregnant mice treated with cortisone; progress report. Pediatrics 1951; 8: 527-33.

${ }^{15}$ DeCosta EJ, Abelman MA. Cortisone and pregnancy. An experimental and clinical study of the effects of cortisone on gestation. Am J Obstet Gynecol 1952: 64: 746-65.

${ }^{16}$ Bongiovanni AM, McPadden AJ. Steroids during pregnancy and possible fetal consequences. Fertil Steril 1960; 11: 181-6.

${ }^{17}$ Warrell DW, Taylor R. Outcome for the foetus of mothers receiving prednisolone during pregnancy. Lancet 1968; 1: 117-8.

${ }^{18}$ Hensleigh PA, Kauffman RE. Maternal absorption and placental transfer of sulfasalazine. Am J Obstet Gynecol 1977; 127: 443-4.

${ }^{19}$ Azad Khan AK, Truelove SC. Placental and mammary transfer of sulphasalazine. Br Med J 1979; 2: 1553.

${ }^{20} J a ̈ r n e r o t ~ G$, Into-Malmberg M-B. Sulphasalazine treatment during breast feeding. Scand $J$ Gastroenterol 1979; 14: 869-71. 